\title{
Behavioral niche partitioning in a sympatric tiger beetle assemblage and implications for the endangered Salt Creek tiger beetle
}

How behavioral patterns are related to niche partitioning is an important question in understanding how closely related species within ecological communities function. Behavioral niche partitioning associated with thermoregulation is well documented in tiger beetles as a group. Co-occurring species of salt flat tiger beetles have adapted many thermoregulatory behaviors to cope with this harsh ecosystem. On first examination these beetles appear to occur in overlapping microhabitats and therefore compete for resources. To determine if behavioral niche partitioning is allowing multiple species to occur within the same harsh salt flat ecosystem we observed Cicindela nevadica lincolniana, Cicindela circumpicta, Cicindela fulgida, and Cicindela togata between 8:00 hours and 21:00 hours and recorded all behaviors related to thermoregulation using a digital voice recorder. Results of this study strongly indicate that competition among these species for resources has been reduced by the adaptation of different thermoregulatory behaviors such as spending time in shallow water, avoiding the sun during the hottest parts of the day, and by positioning their body against or away from the soil. The endangered $C$. $n$. lincolniana appears to rely most heavily on the shallow water of seeps for their diurnal foraging behavior (potentially limiting their foraging habitat), but with the advantage of allowing foraging during the hottest times of the day when potential competitors are less frequent. Ironically, this association also may help explain $C . n$. lincolniana's susceptibility to extinction: beyond the loss of saline wetlands generally, limited seeps and pools even within remaining saline habitat may represent a further habitat limitation within an already limited habitat. 
1 Behavioral niche partitioning in a sympatric tiger beetle assemblage and implications for

2 the endangered Salt Creek tiger beetle

3 Authors:

4 Tierney R. Brosius (corresponding author)

5 Assistant Professor of Biology

6 Augustana College

$763938^{\text {th }}$ Street

8 Rock Island, IL 61201

9 402-750-6713

10 TierneyBrosius@augustana.edu

11

12 Leon Higley

13 Professor of Applied Ecology

14 Biochemistry Hall

15 University of Nebraska - Lincoln

16 Lincoln, NE 68583-0760

17 402-560-6684

18 lhigley@drshigley.com 


\section{Abstract}

How behavioral patterns are related to niche partitioning is an important question in

21 understanding how closely related species within ecological communities function. Behavioral

22 niche partitioning associated with thermoregulation is well documented in tiger beetles as a

23 group. Co-occurring species of salt flat tiger beetles have adapted many thermoregulatory

24 behaviors to cope with this harsh ecosystem. On first examination these beetles appear to occur in

25 overlapping microhabitats and therefore compete for resources. To determine if behavioral niche

26 partitioning is allowing multiple species to occur within the same harsh salt flat ecosystem we

27 observed Cicindela nevadica lincolniana, Cicindela circumpicta, Cicindela

28 fulgida, and Cicindela togata between 8:00 hours and 21:00 hours and recorded all behaviors

29 related to thermoregulation using a digital voice recorder. Results of this study strongly indicate

30 that competition among these species for resources has been reduced by the adaptation of

31 different thermoregulatory behaviors such as spending time in shallow water, avoiding the sun

32 during the hottest parts of the day, and by positioning their body against or away from the soil.

33 The endangered C. n. lincolniana appears to rely most heavily on the shallow water of seeps for

34 their diurnal foraging behavior (potentially limiting their foraging habitat), but with the advantage

35 of allowing foraging during the hottest times of the day when potential competitors are less

36 frequent. Ironically, this association also may help explain $C$. $n$. lincolniana's susceptibility to

37 extinction: beyond the loss of saline wetlands generally, limited seeps and pools even within

38 remaining saline habitat may represent a further habitat limitation within an already limited

39 habitat. 
40

\section{Introduction}

Competition is one of the main forces driving niche partitioning and, consequently, speciation. Interspecific competition may lead to segregation among or within habitats followed by adaptations to different microhabitats (Schultz \& Hadley, 1987). Ultimately, adaptation through selection is genetic but the phenotypic expression of selection may take many forms. Although we commonly think of physiological and morphological changes as products of selection through niche partitioning, variation in the behavior of sympatric species also can be a mechanism for niche partitioning.

Harsh environments, where the biota is reduced and physiological adaptation is essential

for survival, present ideal laboratories for examining the interplay of adaptation and competition. In such systems, the strong selection pressure associated with the physical environment provides a stage upon which interspecific competition plays. Saline wetlands, and their associated salt flats are one such harsh environment.

The saline wetlands of eastern Nebraska are home to a unique cast of adapted organisms. Along with saline requirements in these organisms' life histories, many also are adapted to tolerate the harsh, desert-like environment typically associated with salt flats during the summer months (Farrar \& Gersib, 1991). Within this environment exists a large assemblage of congeneric, sympatric tiger beetle species, including the endangered Cicindela nevadica lincolniana (Willis, 1967; Spomer \& Higley, 1993; Spomer, Higley, \& Hoback, 1997). Because of the uniqueness of this environment and the endangered status of one of these beetle species much attention has been given to this group of tiger beetles.

Behaviors that serve to partition resources and reduce physiological stress have been examined for many species of tiger beetles, Cicindelidae, but much remains to be discovered about the diversity and functions of tiger beetle behavior (Pearson \& Mury, 1979; Pearson 1980; Pearson \& Stemberger, 1980; Pearson \& Knisley, 1985; Ganeshaiah \& Belavadi, 1986; Schultz \& Hadley, 1987; Hoback et al., 2000; Hoback, Higley, \& Stanley et al., 2001; Romey \& Knisley, 2002). Past and current research supports the theory that these tiger beetles are using oviposition 
67 as a mechanism for niche partitioning (Hoback et al., 2000; Hoback, Higley, \& Stanley, 2001;

68 Allgeier, 2005). Tiger beetle larvae do not move more than a few $\mathrm{cm}$ from where their eggs are

69 originally deposited by the female. Among three salt marsh tiger beetle species $(C . n$.

70 lincolniana, C. circumpicta, and C. togata) we observed oviposition differences based on soil

71 salinity (Algeier 2006; Brosius 2010). This unique life history trait, along with the larval

72 dependence on limited prey resources for proper development (Mury Meyer, 1987), emphasizes

73 the importance of the location chosen for oviposition.

$74 \quad$ Prey also are essential to adult female fecundity. The amount of prey consumed by adult

75 females is directly tied to their ability to lay greater numbers of eggs (Pearson \& Knisley, 1985).

76 The ability to lay more eggs can be important to the success of individual populations given high

77 mortality in the larval stages. For example, Shelford (1913) documented the mortality of some

78 populations of Cicindela scutellaris to be as high as $80 \%$ due to the parasitoid Anthrax sp., and

79 Knisley and Shultz (1997) documented a mortality rate upwards around 63\% from tiphiid wasps.

80 Because females must gain enough caloric resources for egg production and development,

81 it is likely that adult tiger beetle assemblages have evolved behaviors to reduce interspecific

82 competition as adults. In particular, beyond direct competition for prey (e.g., Hoback et al.,

83 2001), competition may be mediated through partitioning of foraging habitats: spatially,

84 seasonally, or temporally. In this partitioning, temperature tolerance to the foraging habitat may

85 play a key role.

86 There is a long history of thermoregulation studies that focus on tiger beetles and that link

87 thermoregulation behaviors to resource partitioning (Dreisig, 1980; Dreisig, 1981; Dreisig, 1984;

88 Dreisig, 1985; Morgan, 1985; Pearson \& Lederhouse, 1987; Schultz \& Hadley, 1987; Schultz,

89 Quinlan, \& Hadley, 1991; Schultz, 1998; Hoback, Higley, \& Stanley, 2001; Romey \& Knisley,

90 2002). Many tiger beetles are found in environments where temperatures are capable of

91 exceeding $60^{\circ} \mathrm{C}$, a lethal temperature for most insect species (Hadley 1994). From these studies it

92 is clear that Cicindela are capable of regulating their body temperatures by changing their body 
93 orientation and shuttling between microclimates. Adult tiger beetles spend a high percentage of

94 their day balancing foraging behavior with thermoregulatory behavior. Pearson and Stemberger

95 (1980) determined that the gain of one hour of additional foraging could increase the biomass of

96 ingested prey by as much as $20 \%$. This increase in prey would translate into an increase in egg

97 production for adult females.

98 Physiological character divergence in species' ability to cope with temperatures could be a

99 mechanism to reduce intraguild predation. Differences in heat tolerances between species is a

100 likely mechanism to reduce competition, however, a close examination of lethal maximum

101 temperature of 13 tiger beetle species near Willcox, Arizona, USA revealed very few differences

102 between upper heat tolerances among species (Pearson \& Lederhouse 1987). Out of the 13

103 species examined in this study only two were found to be significantly different and the

104 difference was less than one degree from the overall mean of $48.1^{\circ} \mathrm{C}$. Hoback, Higley, \&

105 Stanley (2001) determined the lethal maximum temperature for two species of tiger beetles

106 (Cicindela circumpicta and Cicindela togata) within the complex of co-occurring species in the

107 eastern saline wetlands of Nebraska and found no differences between species, with results

108 similar to values observed by Pearson and Lederhouse (1987) with different Cicindela species.

109 While tiger beetle species may have some variation in their ability to cope with different degrees

110 of humidity and temperature (Pearson \& Lederhouse, 1987; Schultz \& Hadley, 1987; Schultz,

111 Quinlan, \& Hadley, 1991) physiological differences cannot account for all behavioral differences

112 observed in the field.

113 To determine the evolutionary cause for such differences, Hoback, Higley, and Stanley

114 (2001) investigated lethal high temperatures, prey base, prey size, mobility, and the effect of

115 direct predation of $C$. togata by $C$. circumpicta. Laboratory studies that investigated feeding

116 behavior of C. togata in both the absence and presence (separated by a clear pane of glass) of $C$.

117 circumpicta indicated that C. togata feeding behavior was negatively affected by the presence of 
118 C. circumpicta. These results coupled with field observations strongly indicated that intra-guild

119 predation was possible among salt marsh tiger beetles.

120 In the case of C. n. lincolniana and its co-occurring Cicindela species it is likely that

121 similar evolutionary forces are at work as seen in earlier studies are at work. Past research

122 strongly suggests that behaviors associated with the reduction of predation, thermoregulation,

123 foraging, and predator avoidance may reduce competition among sympatric, adult tiger beetles

124 (Pearson \& Mury, 1979; Schultz \& Hadley, 1987; Pearson \& Juliano, 1991; Romey \& Knisley,

125 2002). Consequently, we examined diurnal behavior of foraging salt marsh Cicindela species,

126 with particular focus on potential differences in thermoregulatory behaviors. In particular, given

127 the endangered species status of $C$. n. lincolniana, we were interested in identifying any unique

128 adaptations that might contribute to population declines different from the other salt marsh tiger

129 beetle species.

130 Methods and Materials

131 During the summer of 2007 initial observations were made of three species of saline

132 adapted tiger beetles: C. circumpicta, C. togata, and, C. n. lincolniana at the Arbor Lake

133 Complex, Lincoln, NE. From these initial observations it appeared that these tiger beetles exhibit

134 a large variety of behaviors and use a wide range of microhabitats. Behaviors associated with

135 thermoregulation were of particular interest. Based on the 2007 data, an ethogram or catalogue of

136 discrete behaviors was developed. Observations were classified specifically as states, events, and

137 behaviors.

138 "States" described physical aspects of the environments, here, temperature, light, and

139 substrate. Temperature included measures of soil-surface temperature, $1 \mathrm{~cm}$ above the soil

140 (comparable to tiger beetle body height), and ambient (1m) air temperatures. Light indicated if

141 the subject was standing in the sun or shade. Substrate indicated if the subject was on dry soil,

142 mud, or shallow water (typically on water near seeps or on algal mats along stream margins).

143 "Behaviors" included running, stilting, basking, and standing. Stilting occurs when the

144 tiger beetle holds itself up off of the substrate with its front two legs extended straight downward. 
145 Often the beetles appear to be standing at a $45^{\circ}$ angle from the vertical. Stilting occurs during the

146 hottest time of day in an effort to reduce surface area and keep bodies away from the hot soil

147 surface (Pearson \& Vogler, 2001). Basking occurs when the tiger beetle presses its body up to the

148 substrate in an effort to warm its body in the early morning hours (Pearson \& Vogler, 2001).

149 "Events" were recorded when individuals exhibited a behavior that had no measurable

150 time duration. Events included mandible dipping (dipping mandibles into the substrate beetles

151 were are standing on), wing pumping (a quick opening and closing of their elytra), flight (this

152 event had a measurable time duration but we almost always lost track of the individual), and

153 abdomen dipping (the individual would dip its abdomen into the water by doing what appeared to

154 be a quick pushup).

155 Behaviors of four co-occurring species of tiger beetles were examined on 20 June 2008,

15630 June 2008, 7 July 2008, 23 June 2009, and 2 July 2009. Dates were chosen based on the

157 predicted weather. We chose days that were predicted to have average or above average

158 temperature with no precipitation. Species included C. circumpicta and C. togata, C. $n$.

159 lincolniana, and the spring-fall species C. fulgida (which occasionally occurred in early

160 summer). Behavior, states, and events were recorded using digital voice recorders and later

161 transcribed using the program JWatcher ${ }^{\mathrm{TM}}$ (Version 1.0). One recording was made for each hour

162 in the field.

163 For each hour, three or four observers were randomly assigned a species to observe.

164 Recordings were made from the first individual of that species the observer could locate using

165 close-focus binoculars. At the start of each recording the observer noted the date, time, species,

166 and, observer name. The observer watched one individual as long as they could in a 30 minute

167 period. If recordings were less than 10 minutes in length the observer recorded a second

168 individual of the same species for that hour. On the rare occasion that no species of that

169 individual could be found (after at least 15 minutes of looking) the observer selected the first

170 tiger beetle that they could find for recording observations. Along with these behaviors hourly 
171 temperatures were recorded. The surface temperature was taken from the area near where the

172 recordings were being made. Temperature measurements were taken at 1 meter and $1 \mathrm{~cm}$

173 elevation from the same location. Because tiger beetle's bodies are approximately $1 \mathrm{~cm}$ above the

174 soil surface, we used $1 \mathrm{~cm}$ measurement to reflect the temperatures being experienced by the

175 beetles.

176 The data were entered into the program JWatcher. For each block of time, we averaged

177 time spent exhibiting individual behaviors (basking, running, standing, and stilting), time spent in

178 sun or shade, and time spent on type of substrate (mud, dry soil, and water). Because times that

179 each individual was watched varied, we converted the time spent to percentages for species

180 comparisons. Events were averaged by hour by species.

181 Analysis. Statistical differences were examined by using non-parametric approaches,

182 because data were not normally distributed and could not be transformed to meet normality

183 requirements. We used non-parametric procedures in GraphPad InStat (version 3.10 for

184 Windows, GraphPad Software, San Diego California USA, www.graphpad.com) for analyses.

185 These procedures included Mann-Whitney tests or non-parametric ANOVA with Kruskal-Wallis

186 Test (corrected for ties) for overall significance, and Dunn's Multiple Comparison for separating

187 species where the Kurskal- Wallis indicated a significant overall effect. The logic of statistical

188 choices and limitations follow that of Motulky (2009).

189 Responses to state and behavior variables were analyzed by determining the mean time in

190 a state for two periods: morning (8:00-11:00) and afternoon (11:00-21:00). The decision to

191 subdivide the day into these two periods was made a priori based on the expectation of

192 substantial temperature and behavioral differences at these times of day (based on published

193 research and our own previous observations). Events were analyzed based on mean counts per

194 day (i.e., the number of occurrences of each event). States, behaviors, and events were analyzed

195 across species and within species. For analysis purposes the combination of day and different

196 individuals within a species represents our replications. Additionally, randomly assigning 
different observers to record behaviors for different species each hour was used to minimize any

potential bias among observers recording behaviors.

201 time of day and among species (Figures 1-4). Temperatures increased until 15:00 in all

202 measurements (Figure 1). As a result of the absorption of solar radiation, soil temperature became

203 higher than ambient and $1 \mathrm{~cm}$ air temperatures after 11:00. At 08:00 the surface temperature was

204 more than $1^{\circ} \mathrm{C}$ cooler than $1 \mathrm{~cm}$ above the surface and ambient temperature. By 15:00 the surface

205 temperature was $7.9^{\circ} \mathrm{C}$ higher than at $1 \mathrm{~cm}$ above the surface. At 08:00 there was almost no

206 difference between ambient temperature and $1 \mathrm{~cm}$ above the soil surface $\left(0.12^{\circ} \mathrm{C}\right)$. At $16: 00$ hours

207 the difference rose to $1.9^{\circ} \mathrm{C}$. Temperatures dropped dramatically between 20:00 and 21:00. At 1

$208 \mathrm{~cm}$ above the salt flat surface, temperatures dropped $5.4^{\circ} \mathrm{C}$.

209 Time spent in the sun was directly linked to the time of day and, therefore, temperature.

210 For all species time spent in the sun was significantly higher in the morning (08:00-11:00) when

211 the salt flat temperatures were the coolest (Figure 2, Table 1). As temperatures rose the amount of

212 time spent in the shade increased for all species (Figure 2). Significant differences in percentages

213 of time spent in the sun were found between species. Cicindela nevadica lincolniana spent the

214 most time in the sun throughout the day (77.1\% of their total time) (Figure 2, Table 1).

215 Cicindela togata spent the most amount of time on dry soils (Figure 3, Table 2).

216 Cicindela nevadica lincolniana spent significantly more time standing on the damp surfaces and

217 in the shallow water of the seeps than the other species observed (Figure 3, Table 2). Both $C$.

218 circumpicta and C. fulgida spent the majority of their time on damp substrate as opposed to dry

219 soil (Figures 3a \& 3c, Table 2). Cicindela circumpicta spent more time on dry substrate when

220 temperatures rose in the late afternoon (Figure 3a, Table 2). Cicindela fulgida spent the most

221 amount of their time on damp substrate $(60.1 \%$ total) and time spent on damp substrate increased

222 with temperature (Figure 3c, Table 3). 
224 water (at margins of seeps and streams). Of the species observed, during the hottest parts of the

225 day C. $n$. lincolniana spent over a third of the time in water, while other species spent little or no

226 time in water (Figure 3, Table 4).

227 Behaviors. All four species of tiger beetle spent a large portion of their time alternating

228 between standing and running (Figure 4). This reflects typical tiger beetle foraging behavior

229 where they run in short bursts or stand watching for prey (Pearson \& Juliano, 1991). Cicindela

230 togata had the largest shift between running and standing in the middle of the day (Figure 4d).

231 Basking was almost always associated with morning hours (before 11:00) and evening hours

232 (after 16:00), with more than three times more basking in the morning than later. Across species,

233 basking occurred $15.5 \%$ of the time before 11:00 versus 5.1\% of time after 11:00 (Mann-Whitney

$234 \mathrm{U}=13.86, \mathrm{P}<0.0001)$. This difference lined up with the coolest hours of the day. Stilting was

235 almost completely associated with the middle parts of the day for all four species. Cicindela

236 circumpicta spent more time basking in the early hours (Figure 4a).

237 Events. The total events per hour were averaged over the entire day for all four species

238 (Table 5). Cicindela nevadica lincolniana was the only species to display abdomen dipping into

239 water (Table 5). Similarly, C. n. lincolniana averaged 78.05 mandible dips per hour, which was

240 far greater than $C$. circumpicta which was the next highest at 5.44 mandible dips per hour.

241 Cicindela togata averaged 0.88 flights per hour, which was greater than C. fulgida which was the

242 next highest at 0.51 flights per hour. Cicindela togata appeared to make many short flights during

243 the 8:00 time block but short flights seemed to have no other significant correlation to time of day

244 for any other tiger beetle species (Figure 5). Wing pumping occurred in greater frequency in C. $n$.

245 lincolniana earlier in the day but appeared to occur with greater frequency later in the day for $C$.

246 circumpicta (Figure 6).

247 Discussion

248 The high surface temperatures reached by the salt flats in the middle of the day are a

249 challenge for organisms living in this ecosystem, including tiger beetles. The results of this study 
suggest that these species have evolved multiple mechanisms for coping with the high

251 temperatures found on the salt flats. Because these mechanisms vary among species, these results

252 imply that co-occurring species of adult tiger beetles within this system are segregating their

253 foraging through behavioral differences associated with temperature.

254 Shade-seeking behavior during the heat of the day is a common behavior seen in many

255 organisms. Interestingly, $C$. $n$. lincolniana is very active during the hottest part of the day while

256 other species of salt flat tiger beetles spend much of their time seeking refuge in the shade. This

257 difference is probably not due to differences in physiology, but rather associated with differences

258 in their behavior. Unlike other species C. n. lincolniana spends over a third of its time foraging in

259 shallow seeps. During this foraging, what we observed as mandible dipping is probably two

260 different types of behavior. Tiger beetles drink water by sinking their mandibles into a damp

261 substrate. We observed tiger beetles taking a few seconds to hydrate using this behavior, however,

262 when mandible dipping C. $n$. lincolniana would frequently come up with a small insect larva that

263 it would quickly consume. Even in the hottest part of the day C. $n$. lincolniana was able to forage

264 while in the shade of the salt grass growing in the seeps. Additionally, the seemingly unique

265 behavior of abdomen dipping by C. $n$. lincolniana suggests that wetting the abdomen might be

266 another mechanism for heat reduction.

267 Differences in habitat use and foraging behavior allow C. $n$. lincolniana to be active

268 during the hottest part of the day. This unique foraging behavior probably explains the large

269 difference in mandible dipping frequency between species (Table 4, Figure 5a). There also was a

270 temporal component to foraging by $C$. $n$. lincolniana as they would move out of the water and

271 further out onto the salt flats as evening approached. We observed few other tiger beetle species

272 after 19:00 hours.

273 Cicindela fulgida was the only species of tiger beetles we observed that is classified as a

274 spring-fall species. Spring-fall species of tiger beetle emerge as adults in the fall and overwinter

275 as adults in contrast to summer species which over winter as larvae and emerge as adults in the 
spring. The adult beetles of this species that we were observing had overwintered as adult beetles

277 and had been active as early as March (possibly even warm days in February). We expected that

278 C. fulgida would have a more difficult time dealing with extreme temperatures, and C. fulgida

279 did spent the most time on damp substrate and in the shade (Figure $2 \mathrm{c}$ and $3 \mathrm{c}$ ). This species also

280 spent a large proportion of the morning hours basking (Figure 4c), presumably in an effort to

281 warm their body temperature.

282 Cicindela circumpicta spent more time on dry substrates as temperatures rose during the

283 day. Most of the shade on the salt flats is provided by vegetation which grows on the perimeter of

284 the flat. This area has dry substrate because of the distance from the seep. As the temperatures

285 dropped later in the day C. circumpicta appeared to move back onto damp surfaces to forage

286 (Figure 3a). Cicindela circumpicta also spent a large proportion of their time basking in the early

287 morning hours (Figure 4a). It is possible that the larger body mass of C. circumpicta requires

288 more basking to raise its body temperature.

289 Cicindela togata spent the most time on dry surfaces. Unlike C. circumpicta who moved

290 to dry surfaces during the hottest part of the day and moved back to damp surfaces C. togata

291 appears to spend all of its time on dry soils. The time spent on damp soils in the morning is likely

292 a result of the lack of dry soil due to morning condensation. Cicindela circumpicta and C. togata

293 have the same tolerance to heat yet they forage in different microhabitats on the flats (Hoback,

294 Higley, \& Stanley, 2001). Hoback, Higley, \& Stanley (2001) theorized that microhabitat

295 differences in foraging was a consequence of C. togata avoiding being preyed upon by $C$.

296 circumpicta. In support of this notion, laboratory studies demonstrated that C. togata's behavior

297 is modified by the presence of $C$. circumpicta. Because $C$. circumpicta is the largest of the salt

298 marsh tiger beetles, other species may have adapted different foraging behaviors to avoid contact

299 with C. circumpicta to avoid predation as well as to reduce competition in foraging.

300 An alternative (or possibly complimentary) explanation for C. togata use of microhabits

301 was suggested by one of our anonymous reviewers. Because C. togata has the smallest body size 
302 and longer legs than other tiger beetles we studied, C. togata can heat and cool more rapidly than

303 other species (Pearson \& Vogler, 2001). Given this advantage, C. togata may be able to use dry

304 substrates when foraging more effectively than other species (who may have great

305 thermoregulation issues).

306 Wing pumping by tiger beetles is thought to be a thermoregulatory behavior to release

307 heat (Pearson \& Vogler, 2001), but C. togata (which had the highest per hour average) pumped its

308 wings at a greater frequency in the morning. Cicindela fulgida and C. circumpicta both appeared

309 to pump their wings with greater frequency in the middle of the day but did not show a direct

310 association with temperature (Figure 6).

311 Conclusions

312 How tiger beetles allocate their time in relation to temperature has been studied

313 extensively (Dreisig, 1980; Dreisig, 1981; Dreisig, 1984; Dreisig, 1985; Morgan, 1985; Pearson

314 \& Lederhouse, 1987; Schultz \& Hadley, 1987; Schultz, Quinlan, \& Hadley, 1991; Schultz, 1998;

315 Hoback, Higley, \& Stanley, 2001; Romey \& Knisley, 2002). Our results indicate that temperature,

316 as well as potential competitive relationships among Cicindelida species, appears to be tied into

317 what substrate beetles chose to occur on, whether or not they chose to spend time in the sunlight,

318 and what behaviors they exhibited.

319 In contrast to what might be expected for the endangered member of this assemblage, $C$.

320 n. lincolniana clearly demonstrates behaviors that afford it advantages in accommodating high

321 temperatures and avoiding potential competition with other tiger beetles. Key to these behaviors

322 is the species reliance shallow water of the seeps for their diurnal foraging behavior (potentially

323 limiting their foraging habitat), but with the advantage of allowing foraging during the hottest

324 times of the day when potential competitors are less frequent. Indeed, by frequenting water, $C . n$.

325 lincolniana was able to remain active in sunlight far more that other species, and maintain its

326 activity over a longer portion of the day.

327 The endangered status of $C$. n. lincolniana requires that those involved with the

328 conservation of this insect examine its habitat requirements closely. Because this beetle appears 
329 to have reduced competition over food resources by adapting to forage in a unique environment

330 they may be more susceptible to habitat destruction. Organisms that are highly specialized, such

331 as $C$. n. lincolniana, are thought to be more susceptible to extinction due to habitat destruction

332 (Kammer, Baumiller, \& Ausich, 1997; Kotiaho et al., 2005). The shallow seeps found in saline

333 wetlands have been destroyed by the channelization of these water ways over the last 100 years.

334 Consequently, the close association of $C$. $n$. lincolniana with seeps and associated shallow pools

335 seems to let $C$. n. lincolniana adults forage at times when temperatures may limit foraging for

336 other saline-adapted tiger beetles. Ironically, this association also may help explain C. $n$.

337 lincolniana's susceptibility to extinction: beyond the loss of saline wetlands generally, limited

338 seeps and pools even within remaining saline habitat may represent a further habitat limitation

339 within an already limited habitat.

340 Acknowledgements

341 We thank Drew Tyre for suggestions regarding data analysis, and Lauren Thompson, Mitch

342 Paine, and Carmen Mostek for their assistance with recording behavior data (on some very hot

343 days!). We also thank Lauren for her diligence in helping transcribe hours of behavior recordings.

344 Finally, we appreciate the helpful comments of our anonymous reviewers, particularly the

345 suggestions regarding C. togata foraging behaviors and microhabitat choice.

346 References Cited

347 Allgeier WJ. 2005. The behavioral ecology and abundance of tiger beetles inhabiting the Eastern

348 Saline Wetlands of Nebraska. M.S. Thesis. University of Nebraska, Lincoln Nebraska

349 Dreisig H. 1980. Daily activity, thermoregulation and water loss in the tiger beetle Cicindela

$350 \quad$ hybrid. Oecologia 44:376-389.

351 Dreisig H. 1981. The rate of predation and its temperature dependence in a tiger beetle, Cicindela

352 hybrid. Oikos 36:196-202.

353 Dreisig H. 1984. Control of body temperature in shuttling ectotherms. Journal of Thermal

$354 \quad$ Biology 9:229-233.

355 Dreisig H. 1985. A time budget model of thermoregulation in shuttling ectotherms. Journal of

356 Arid Environments 8:191-205. 
357 Farrar J, Gersib D.. 1991 Nebraska Salt Marshes: Last of the Least. Nebraskaland Magazine

358

359

360

361

362

363

364

365

366

367

368

369

370

371

372

373

374

375

376

377

378

379

380

381

382

383

384

385
69:18-41.

Ganeshaiah KN, Belavadi VV. 1986. Habitat segregation in four species of adult tiger beetles

(Coleoptera: Cicindelidae). Ecological Entomology 11:147-154.

Hadley NF. 1994. Water relations of terrestrial arthropods. Academic Press, New York, NY.

Hoback WW, Golick DA, Svatos TM, Spomer SM, Higley, LG. 2000.

Salinity and shade preferences result in ovipositional differences between sympatric tiger beetle species. Ecological Entomology 25:180-187.

Hoback WW, Higley LG, Stanley DW. 2001. Tigers eating tigers: evidence of intraguild

predation operating in an assemblage of tiger beetles. Ecological Entomology. 26:367-

375.

Kammer TV, Baumiller TK, Ausich WI. 1997. Species longevity as a function of niche breadth:

Evidence from fossil crinoids. Geology 25:219-222.

Kotiaho JS, Kaitala V, Komonen A, Päivinen J. 2005. Predicting the risk of extinction from shared ecological characteristics. Proceedings of the National Academy of Science 102:1963-1967.

Knisley, CB, Schultz TD. 1997. The Biology of Tiger Beetles and a Guide to South Atlantic States. Special Publication No. 5 Virginia Museum of Natural History, Martinsville, VA.

Morgan, KR 1985. Body temperature regulation and terrestrial activity in the ectothermic beetle

Cicindela tranquebarica. Physiological Zoology 58:29-37

Mury Meyer, EJ. 1987. Asymmetric resource use in two syntopic species of larval tiger beetles

(Cicindelidae). Oikos 50:16-175.

Motulsky, HJ. 2009. GraphPad InStat 3.0 User's Guide, GraphPad Software, Inc., San Diego

California USA, www.graphpad.com.

Pearson, DL, Vogler AP. 2001. Tiger beetles: the evolution, ecology, and diversity of the cicindelids. Cornell University Press, Ithaca, NY.

Pearson DL. 1980.Patterns of limiting similarity in tropical forest tiger beetles (Coleoptera:

Cicindelidae). Biotropica 12:195-204. 
386 Pearson DL, Juliano SA. 1991. Mandible length ratios as a mechanism for co-occurrence:

Evidence from a world-wide comparison of tiger beetle assemblages (Cicindelidae). Oikos 61:223-233.

Pearson DL, Knisley CB. 1985. Evidence for food as a limiting source in the life cycle of tiger beetles (Coleoptera: Cicindelidae). Oikos 45:161-168.

Romey WL, Knisley CB. 2002. Microhabitat segregation of two Utah sand dune tiger beetles (Coleoptera: Cicindelidae). Southwestern Entomologist 147:169-174.

tiger beetle species (Coleoptera: Cicindelidae). Okios 50:247-255.

Pearson DL, Mury EJ. 1979. Character divergence and convergence among tiger beetles

(Coleoptera: Cicindelidae). Ecology 60: 557-566.

Pearson DL, Stemberger SL. 1980. Competition, body size, and relative energy balance of adult tiger beetles (Coleoptera: Cicindelidae). American Midlands Naturalist 104:373-377.

Pearson DL, Vogler AP. 2001. Tiger beetles: the evolution, ecology, and diversity of the cicindelids. Cornell University Press, Ithaca, NY.

Schultz TC. 1998. The utilization of patchy thermal microhabitats by ectothermic insect predator, Cicindela sexguttata. Ecological Entomology 23:444-450.

Schultz TC, Quinlan MC, Hadley NF. 1991. Preferred body temperature, metabolic physiology, and water balance of adult Cicindela longilabris: A comparison of populations from boreal habitats and climatic refugia. Physiological Zoology 65:226-242.

413 Spomer SM, Higley LG. 1993. Population and distribution of the Salt Creek 
416 Spomer SM, Higley LG, Hoback WW. 1997. Nebraska's salt marsh tigers.

417 Museum Notes University of Nebraska 97:1-4.

418 Willis HL. 1967. Bionomics and zoogeography of tiger beetles of saline habitats in the central 419 United States (Coleoptera: Cicindelidae). University of Kansas Science Bulletin 47:145-

420 313. 


\section{Table 1 (on next page)}

Comparison of proportion of time spent in the sun by C. circumpicta, C. fulgida, C. $n$. lincolniana, and C. togata.

Morning and afternoon/evening differences across species were evaluated with a MannWhitney test. Species differences (within morning or afternoon/evening) were determined by Kruskal-Wallis Test through non-parametric ANOVA (K-W test statistic corrected for ties and $P$ determined from chi-square distribution). Significant species comparisons were determined by Dunn's Multiple Comparisons Test (only results with $\mathrm{P}<0.05$ are shown.) 
Table 1. Comparison of proportion of time spent in the sun by C. circumpicta, C. fulgida, C. $n$. lincolniana , and C. togata. Morning and afternoon/evening differences across species were evaluated with a Mann-Whitney test. Species differences (within morning or afternoon/evening) were determined by Kruskal-Wallis Test through non-parametric ANOVA (K-W test statistic corrected for ties and P determined from chi-square distribution). Significant species comparisons were determined by Dunn's Multiple Comparisons Test (only results with $\mathrm{P}<0.05$ are shown.)

\begin{tabular}{|c|c|c|c|c|c|}
\hline \multicolumn{6}{|c|}{ Proportion of Time in Sun } \\
\hline & 8:00-21 & & & M-W U & $\mathbf{P}>\mathbf{F}$ \\
\hline \multicolumn{4}{|c|}{ Comparison: 8:00-11:00 vs. 11:00-21:00 } & 719.5 & $<0.0001$ \\
\hline Times & $\mathbf{n}$ & Mean & sd & & \\
\hline 8:00-11:00 & 28 & 0.92 & 0.14 & & \\
\hline 11:00-21:00 & 139 & 0.69 & 0.29 & & \\
\hline \multicolumn{4}{|c|}{ 8:00-11:00 } & $\mathbf{K}-\mathbf{W}(\mathrm{df}=3)$ & $\mathbf{P}>X^{2}$ \\
\hline \multicolumn{4}{|c|}{ Comparison: species x species } & 1.43 & ns \\
\hline Species & $\mathbf{n}$ & Mean & sd & & \\
\hline C. circumpicta & 7 & 0.91 & 0.21 & & \\
\hline C. fulgida & 7 & 0.94 & 0.10 & & \\
\hline C. n. lincolniana & 11 & 0.90 & 0.14 & & \\
\hline C. togata & 3 & 0.98 & 0.03 & & \\
\hline \multicolumn{4}{|c|}{ 11:00-21:00 } & $\mathbf{K}-\mathbf{W}(\mathrm{df}=3)$ & $\mathbf{P}>X^{2}$ \\
\hline \multirow{2}{*}{\multicolumn{4}{|c|}{$\begin{array}{l}\text { Comparison: species x species } \\
\text { C. fulgida vs. C. } n \text {. lincolniana }\end{array}$}} & 9.07 & $=0.0283$ \\
\hline & & & & & $<0.05$ \\
\hline Species & $\mathbf{n}$ & Mean & sd & & \\
\hline C. circumpicta & 41 & 0.67 & 0.23 & & \\
\hline C. fulgida & 34 & 0.54 & 0.32 & & \\
\hline C. n. lincolniana & 50 & 0.74 & 0.26 & & \\
\hline C. togata & 14 & 0.62 & 0.41 & & \\
\hline
\end{tabular}




\section{Table 2 (on next page)}

Comparison of proportion of time spent on dry surfaces by $C$. circumpicta, $C$. fulgida, $C$. n. lincolniana , and C. togata.

Morning and afternoon/evening differences across species were evaluated with a MannWhitney test. P values for Mann-Whitney are estimated (not exact) because of tied ranks. Species differences (within morning or afternoon/evening) were determined by Kruskal-Wallis Test through non-parametric ANOVA ( $\mathrm{K}-\mathrm{W}$ test statistic corrected for ties and $\mathrm{P}$ determined from chi-square distribution). Significant species comparisons were determined by Dunn's Multiple Comparisons Test (only results with $\mathrm{P}<0.05$ are shown.) 
Table 2. Comparison of proportion of time spent on dry surfaces by C. circumpicta, C. fulgida, C. n. lincolniana, and C. togata. Morning and afternoon/evening differences across species were evaluated with a Mann-Whitney test. P values for Mann-Whitney are estimated (not exact) because of tied ranks. Species differences (within morning or afternoon/evening) were determined by Kruskal-Wallis Test through non-parametric ANOVA (K-W test statistic corrected for ties and P determined from chi-square distribution). Significant species comparisons were determined by Dunn's Multiple Comparisons Test (only results with $\mathrm{P}<0.05$ are shown.)

\begin{tabular}{|c|c|c|c|c|c|}
\hline \multicolumn{6}{|c|}{ Proportion of Time on Dry Substrate } \\
\hline & 8:00-21: & & & M-W U & $\mathbf{P}>\mathbf{F}$ \\
\hline \multicolumn{4}{|c|}{ Comparison: 8:00-11:00 vs. 11:00-21:00 } & 1514.0 & $=0.0255$ \\
\hline Times & n & Mean & sd & & \\
\hline 8:00-11:00 & 28 & 0.14 & 0.33 & & \\
\hline $11: 00-21: 00$ & 139 & 0.69 & 0.29 & & \\
\hline \multicolumn{4}{|c|}{ 8:00-11:00 } & $\mathbf{K}-\mathbf{W}(\mathrm{df}=3)$ & $\mathbf{P}>X^{2}$ \\
\hline \multicolumn{4}{|c|}{ Comparison: species x species } & 0.7793 & ns \\
\hline Species & $\mathbf{n}$ & Mean & sd & & \\
\hline C. circumpicta & 7 & 0.14 & 0.37 & & \\
\hline C. fulgida & 7 & 0.14 & 0.37 & & \\
\hline C. n. lincolniana & 11 & 0.09 & 0.30 & & \\
\hline C. togata & 3 & 0.33 & 0.57 & & \\
\hline \multicolumn{4}{|c|}{ 11:00-21:00 } & $\mathbf{K}-\mathbf{W}(\mathrm{df}=3)$ & $\mathbf{P}>X^{2}$ \\
\hline \multicolumn{4}{|c|}{ Comparison: species x species } & 42.042 & $<0.0001$ \\
\hline \multicolumn{4}{|c|}{ C. circumpicta vs. C. $n$. lincolniana } & & $<0.001$ \\
\hline \multicolumn{4}{|c|}{ C. circumpicta vs. C. togata } & & $<0.05$ \\
\hline \multicolumn{4}{|c|}{ C. fulgida vs. C. n. lincolniana } & & $<0.01$ \\
\hline \multicolumn{4}{|c|}{ C. fulgida vs. C. togata } & & $<0.01$ \\
\hline \multicolumn{4}{|c|}{ C. n. lincolniana vs. C. togata } & & $<0.001$ \\
\hline Species & $\mathbf{n}$ & Mean & sd & & \\
\hline C. circumpicta & 41 & 0.46 & 0.48 & & \\
\hline C. fulgida & 34 & 0.38 & 0.49 & & \\
\hline C. n. lincolniana & 50 & 0.04 & 0.20 & & \\
\hline C. togata & 14 & 0.62 & 0.34 & & \\
\hline
\end{tabular}




\section{Table 3(on next page)}

Comparison of proportion of time spent on mud by C. circumpicta, C. fulgida, C. $n$. lincolniana, and C. togata.

Morning and afternoon/evening differences across species were evaluated with a MannWhitney test. P values for Mann-Whitney are estimated (not exact) because of tied ranks. Species differences (within morning or afternoon/evening) were determined by Kruskal-Wallis Test through non-parametric ANOVA (K-W test statistic corrected for ties and $\mathrm{P}$ determined from chi-square distribution). Significant species comparisons were determined by Dunn's Multiple Comparisons Test (only results with $\mathrm{P}<0.05$ are shown.) 
Table 3. Comparison of proportion of time spent on mud by C. circumpicta, C. fulgida, C. $n$. lincolniana , and C. togata. Morning and afternoon/evening differences across species were evaluated with a Mann-Whitney test. P values for Mann-Whitney are estimated (not exact) because of tied ranks. Species differences (within morning or afternoon/evening) were determined by Kruskal-Wallis Test through non-parametric ANOVA (K-W test statistic corrected for ties and P determined from chi-square distribution). Significant species comparisons were determined by Dunn's Multiple Comparisons Test (only results with $\mathrm{P}<0.05$ are shown.)

\begin{tabular}{|c|c|c|c|c|c|}
\hline \multicolumn{6}{|c|}{ Proportion of Time on Mud } \\
\hline & 8:00-21: & & & M-W U & $\mathbf{P}>\mathbf{F}$ \\
\hline \multicolumn{4}{|c|}{ Comparison: 8:00-11:00 vs. 11:00-21:00 } & 1645.5 & ns \\
\hline Times & n & Mean & sd & & \\
\hline 8:00-11:00 & 28 & 0.70 & 0.41 & & \\
\hline $11: 00-21: 00$ & 139 & 0.58 & 0.45 & & \\
\hline \multicolumn{4}{|c|}{ 8:00-11:00 } & $\mathbf{K}-\mathbf{W}(\mathrm{df}=3)$ & $\mathbf{P}>X^{2}$ \\
\hline \multicolumn{4}{|c|}{ Comparison: species x species } & 5.900 & ns \\
\hline Species & $\mathbf{n}$ & Mean & sd & & \\
\hline C. circumpicta & 7 & 0.85 & 0.38 & & \\
\hline C. fulgida & 7 & 0.81 & 0.38 & & \\
\hline C. n. lincolniana & 11 & 0.86 & 0.42 & & \\
\hline C. togata & 3 & 0.67 & 0.58 & & \\
\hline \multicolumn{4}{|c|}{ 11:00-21:00 } & $\mathbf{K}-\mathbf{W}(\mathrm{df}=3)$ & $\mathbf{P}>X^{2}$ \\
\hline \multicolumn{4}{|c|}{ Comparison: species x species } & 16.717 & $=0.0008$ \\
\hline \multicolumn{4}{|c|}{ C. circumpicta vs. C. togata } & & $<0.05$ \\
\hline \multicolumn{4}{|c|}{ C. fulgida vs. C. togata } & & $<0.01$ \\
\hline \multicolumn{4}{|c|}{ C. n. lincolniana vs. C. togata } & & $<0.001$ \\
\hline Species & n & Mean & sd & & \\
\hline C. circumpicta & 41 & 0.54 & 0.48 & & \\
\hline C. fulgida & 34 & 0.61 & 0.49 & & \\
\hline C. n. lincolniana & 50 & 0.72 & 0.35 & & \\
\hline C. togata & 14 & 0.13 & 0.34 & & \\
\hline
\end{tabular}




\section{Table 4 (on next page)}

Comparison of proportion of time spent on water by C. circumpicta, C. fulgida, C. $n$. lincolniana, and C. togata.

Morning and afternoon/evening differences across species were evaluated with a MannWhitney test. P values for Mann-Whitney are estimated (not exact) because of tied ranks. Species differences (within morning or afternoon/evening) were determined by Kruskal-Wallis Test through non-parametric ANOVA ( $\mathrm{K}-\mathrm{W}$ test statistic corrected for ties and $\mathrm{P}$ determined from chi-square distribution). Significant species comparisons were determined by Dunn's Multiple Comparisons Test (only results with $\mathrm{P}<0.05$ are shown.) 
Table 4. Comparison of proportion of time spent on water by C. circumpicta, C. fulgida, C. $n$. lincolniana , and C. togata. Morning and afternoon/evening differences across species were evaluated with a Mann-Whitney test. P values for Mann-Whitney are estimated (not exact) because of tied ranks. Species differences (within morning or afternoon/evening) were determined by Kruskal-Wallis Test through non-parametric ANOVA (K-W test statistic corrected for ties and P determined from chi-square distribution). Significant species comparisons were determined by Dunn's Multiple Comparisons Test (only results with $\mathrm{P}<0.05$ are shown.)

\begin{tabular}{|c|c|c|c|c|c|}
\hline \multicolumn{6}{|c|}{ Proportion of Time on Water } \\
\hline & 8:00-21 & & & M-W U & $\mathbf{P}>\mathbf{F}$ \\
\hline \multicolumn{4}{|c|}{ Comparison: 8:00-11:00 vs. 11:00-21:00 } & 1703.0 & ns \\
\hline Times & $\mathbf{n}$ & Mean & sd & & \\
\hline 8:00-11:00 & 28 & 0.15 & 0.30 & & \\
\hline 11:00-21:00 & 139 & 0.08 & 0.22 & & \\
\hline \multicolumn{4}{|c|}{ 8:00-11:00 } & $\mathbf{K}-\mathbf{W}(\mathrm{df}=3)$ & $\mathbf{P}>X^{2}$ \\
\hline \multicolumn{4}{|c|}{ Comparison: species x species } & 13.274 & $=0.0041$ \\
\hline \multicolumn{4}{|c|}{ C. circumpicta vs. C. n. lincolniana } & & $<0.05$ \\
\hline Species & $\mathbf{n}$ & Mean & sd & & \\
\hline C. circumpicta & 7 & 0 & 0 & & \\
\hline C. fulgida & 7 & 0.05 & 0.12 & & \\
\hline C. n. lincolniana & 11 & 0.36 & 0.40 & & \\
\hline C. togata & 3 & 0 & 0 & & \\
\hline \multicolumn{4}{|c|}{ 11:00-21:00 } & $\mathbf{K}-\mathbf{W}(\mathrm{df}=3)$ & $\mathbf{P}>X^{2}$ \\
\hline \multicolumn{4}{|c|}{ Comparison: species x species } & 44.754 & $<0.0001$ \\
\hline \multicolumn{4}{|c|}{ C. n. lincolniana vs. C. circumpicta } & & $<0.001$ \\
\hline \multicolumn{4}{|c|}{ C. n. lincolniana vs. C. fulgida } & & $<0.001$ \\
\hline & \multicolumn{3}{|c|}{ C. n. lincolniana } & & $<0.001$ \\
\hline Species & $\mathbf{n}$ & Mean & sd & & \\
\hline C. circumpicta & 41 & 0 & 0 & & \\
\hline C. fulgida & 34 & 0 & 0.03 & & \\
\hline C. n. lincolniana & 50 & 0.23 & 0.32 & & \\
\hline C. togata & 14 & 0 & 0 & & \\
\hline
\end{tabular}




\section{Table 5 (on next page)}

Means and standard deviations (sd) of total behavioral events per hour averaged daily (11:00-21:00) for C. circumpicta, C. fulgida, C. n. lincolniana, and C. togata.

Significant differences within an event were determined by Kruskal-Wallis Test through nonparametric ANOVA ( $K-W$ test statistic corrected for ties and $\mathrm{P}$ determined from chi-square

distribution, $\mathrm{df}=3$ ). Significant species comparisons were determined by Dunn's Multiple Comparisons Test (only results with $\mathrm{P}<0.05$ are shown). 
Table 5. Means and standard deviations (sd) of total behavioral events per hour averaged daily (11:00-21:00 for C. circumpicta, C. fulgida, C. n. lincolniana, and C. togata. Significant differences within an event were determined by Kruskal-Wallis Test through non-parametric ANOVA (K-W test statistic corrected for ties and P determined from chi-square distribution, df = 3). Significant species comparisons were determined by Dunn's Multiple Comparisons Test (only results with $\mathrm{P}<0.05$ are shown).

\begin{tabular}{|c|c|c|c|c|c|c|c|c|c|}
\hline \multirow[b]{2}{*}{ Species } & \multirow[b]{2}{*}{$\mathbf{n}$} & \multicolumn{2}{|c|}{ Abdomen } & \multicolumn{2}{|c|}{ Mandible Dipping } & \multicolumn{2}{|c|}{ Wing Pumping } & \multicolumn{2}{|c|}{ Flying } \\
\hline & & mean & sd & mean & sd & mean & sd & mean & sd \\
\hline C. circumpicta & 41 & 0 & 0 & 5.4 & 10.3 & 4.0 & 4.8 & 0.20 & 0.46 \\
\hline C. fulgida & 34 & 0 & 0 & 2.5 & 4.2 & 5.2 & 5.4 & 0.59 & 1.02 \\
\hline C. $n . \quad \overline{3}$ & 50 & 0.24 & 1.2 & 75.8 & 99.6 & 3.9 & 4.4 & 0.10 & 0.30 \\
\hline C. togata $\frac{10}{2}$ & 14 & 0 & 0 & 5.8 & 9.7 & 3.9 & 3.5 & 0.57 & 1.16 .5 \\
\hline \multicolumn{2}{|l|}{ Comparison } & K-W & $\mathbf{P}>X^{2}$ & $\mathbf{K}-\mathbf{W}$ & $\mathbf{P}>X^{2}$ & K-W & $\mathbf{P}>X^{2}$ & $\mathbf{K}-\mathbf{W}$ & $\mathbf{P}>X^{2}$ \\
\hline \multirow{3}{*}{\multicolumn{2}{|c|}{$\begin{array}{l}\text { C. n. lincentiana vs. C. circumpicta } \\
\text { C. } n \text {. lincebiana vs. C. fulgida } \\
\text { C. } n \text {. lincebiana vs. C. togata }\end{array}$}} & - & - & 55.50 & $\begin{array}{l}<0.0001 \\
<0.001\end{array}$ & 0.626 & ns & 9.807 & 0.02 \\
\hline & & & & & $<0.001$ & & & & $<0.05$ \\
\hline & & & & & $<0.01$ & & & & \\
\hline
\end{tabular}




\section{Figure 1}

Average mandible dips, wing pumps, and flight events per hour. Average salt flat temperatures by hour.

Temperatures were recorded on the salt flats where observations were made for adult tiger beetles. Temperatures were recorded one meter above the soil surface to determine ambient temperature, one $\mathrm{cm}$ above the soil surface to determine the air temperature the subjects were experiencing, and at the soil surface.

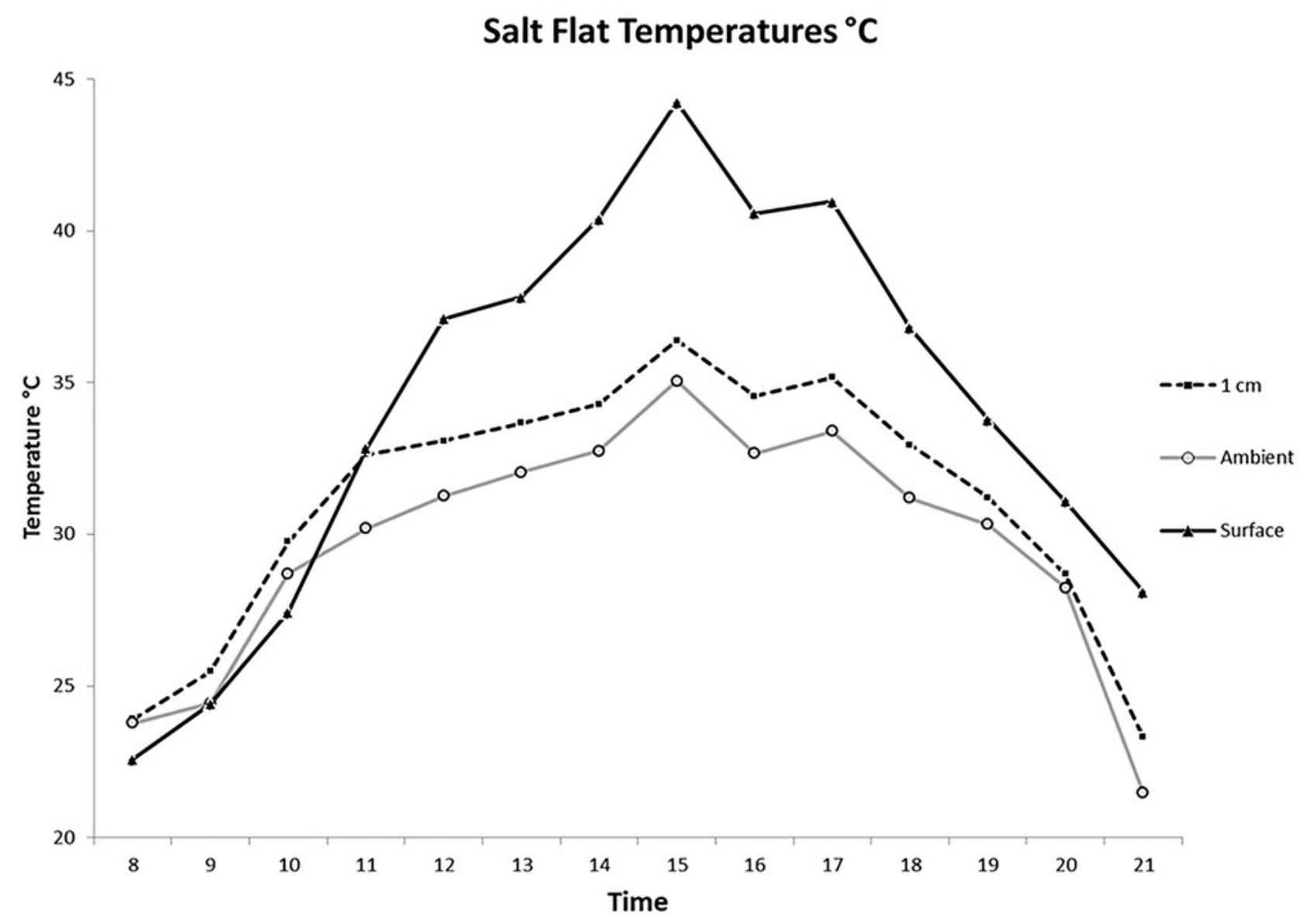




\section{Figure 2}

Time spent in sun or shade by tiger beetle species.

Proportion of time spent in the sun or the shade between 8:00 and 21:00 hours (bars on graph) and soil surface temperature of the salt flats (dotted line) over those hours for four species of salt flat tiger beetle: a) $C$. circumpicta, b) $C$. n. lincolniana, c) $C$. fulgida, and d) $C$. togata.

a)

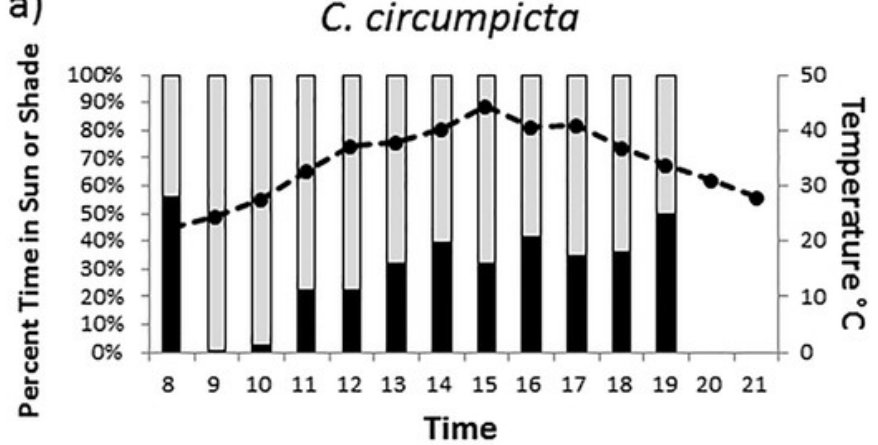

c)

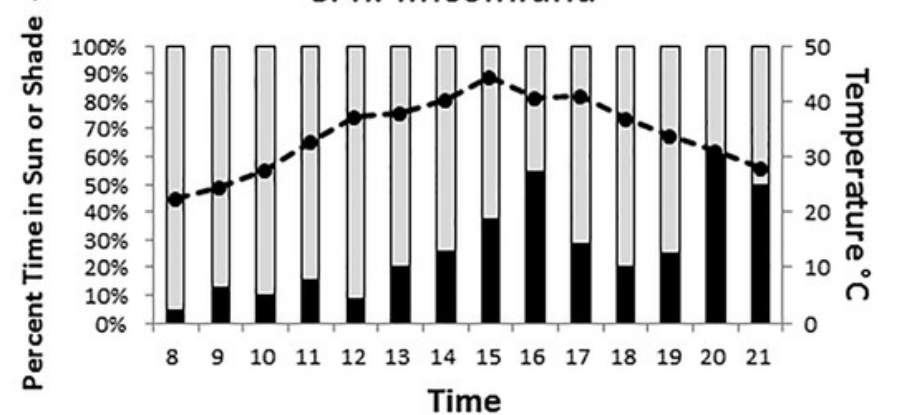

b)

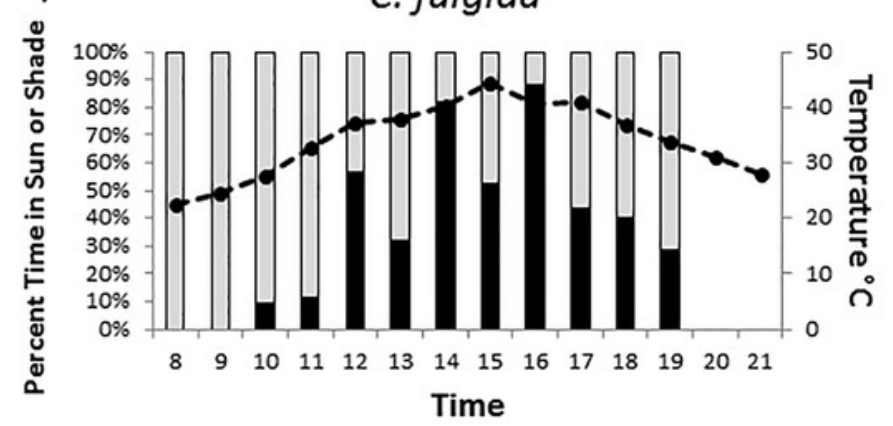

d)

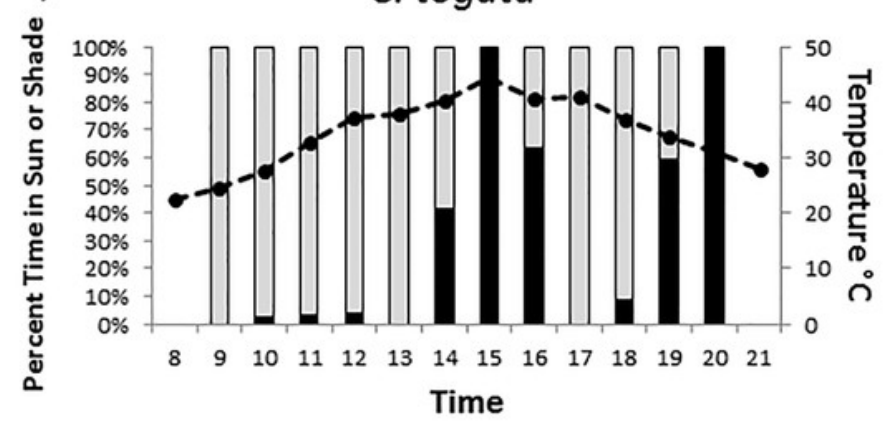

shade sun 


\section{Figure 3}

Time spent on different substrates by tiger beetle species.

Proportion of time spent on wet soil (mud), dry soil, and in shallow water between 8:00 and 21:00 hours (bars on graph) and soil surface temperature of the salt flats (dotted line) over those hours for four species of salt flat tiger beetle: a) $C$. circumpicta, b) $C$. n. lincolniana, c) C. fulgida, and d) C. togata.

a)

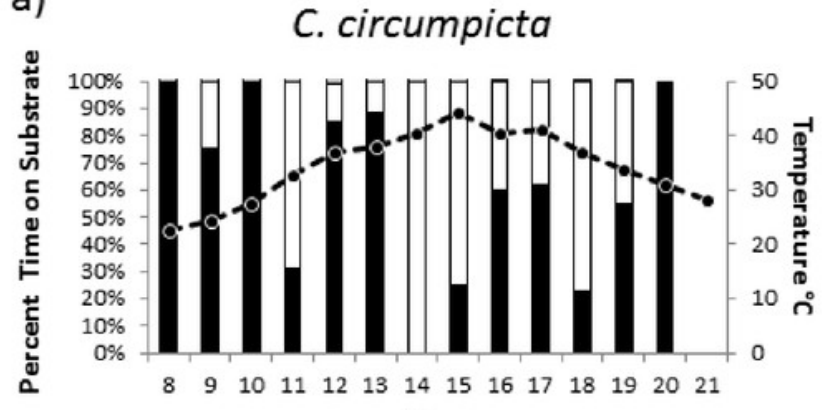

Time

c)

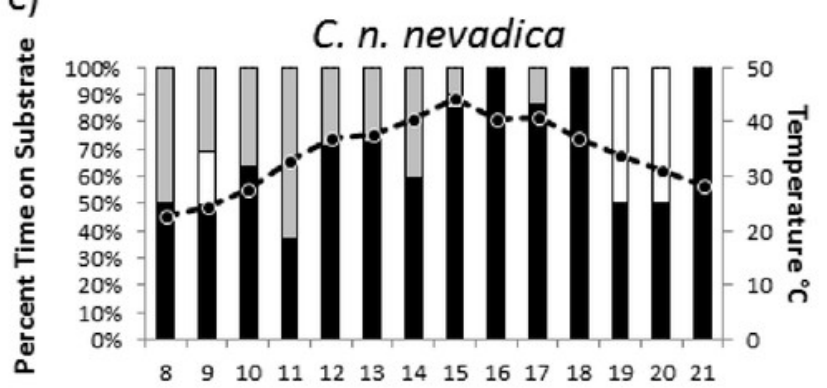

Time b)

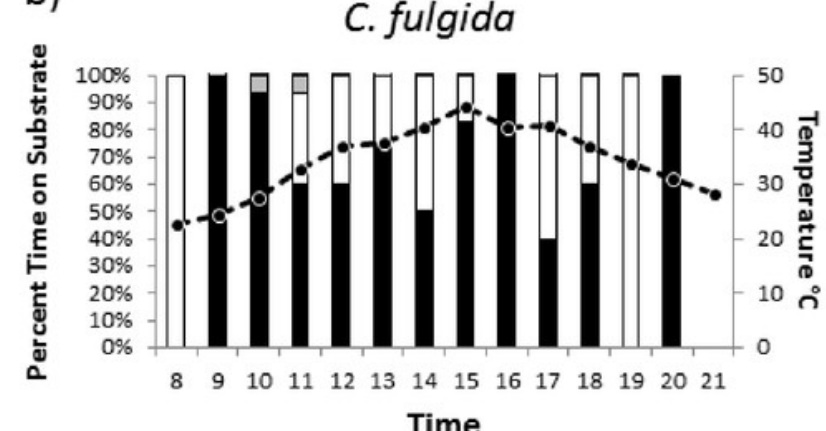

d)

C. togata

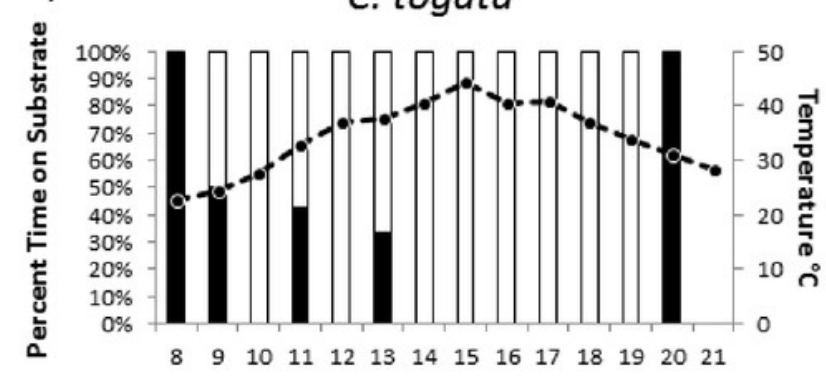

Time

mud

water

dry 


\section{Figure 4}

Time spent engaging in thermoregulatory behavior.

Proportion of time spent in four distinct behaviors related to thermoregulation between 8:00 and 21:00 hours (bars on graph), and soil surface temperature of the salt flats (dotted line) over those hours for four species of salt flat tiger beetle: a) C. circumpicta, b) $C . n$. lincolniana, c) C. fulgida, and d) C. togata.

a)

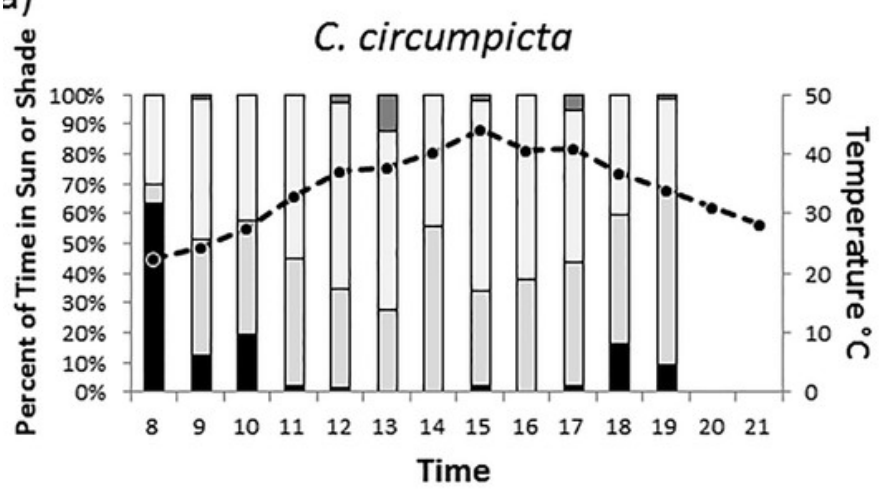

:)

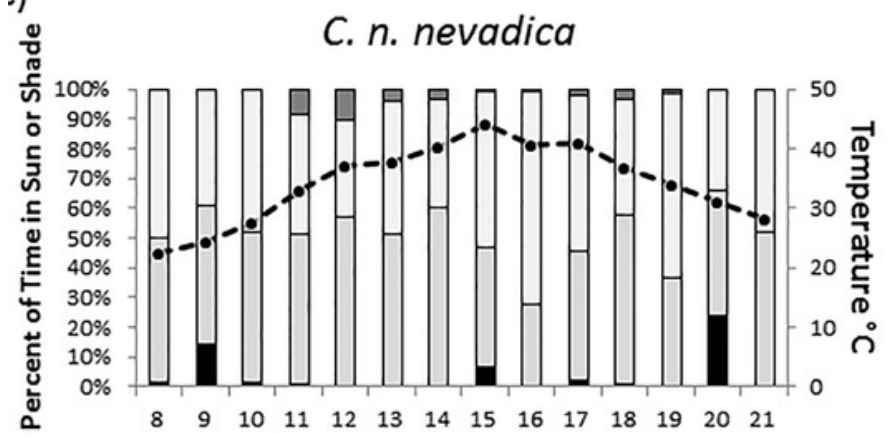

Time b)

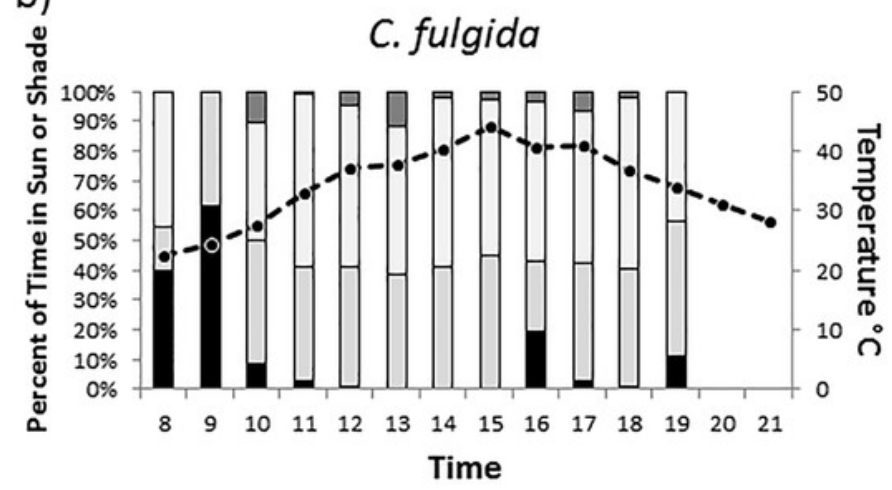

d)

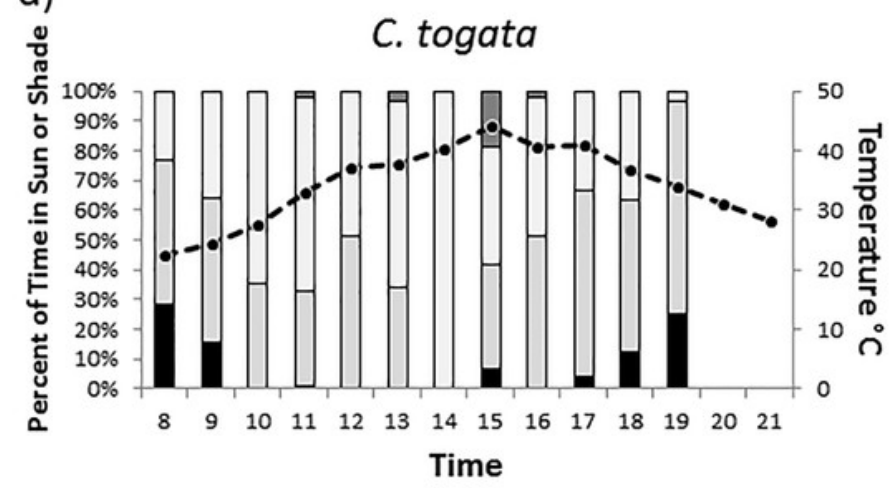
basking running standing stilting 


\section{Figure 5}

Average mandible dips, wing pumps, and flight events per hour.

A) Average recorded mandible dipping events per hour of observation for C. $n$. lincolniana and C. circumpicta (bars on graph), and soil surface temperature of the salt flats over those hours (dotted line); B) Average recorded wing pumping events per hour of observation for $C$. n. lincolniana, C. fulgida, and C. circumpicta (bars on graph), and soil surface temperature of the salt flats (dotted line) over those hours; and C) Average recorded flight events per hour of observation for $C$. n. lincolniana, $C$. togata, and C. circumpicta and surface temperature of the salt flats over those hours. 

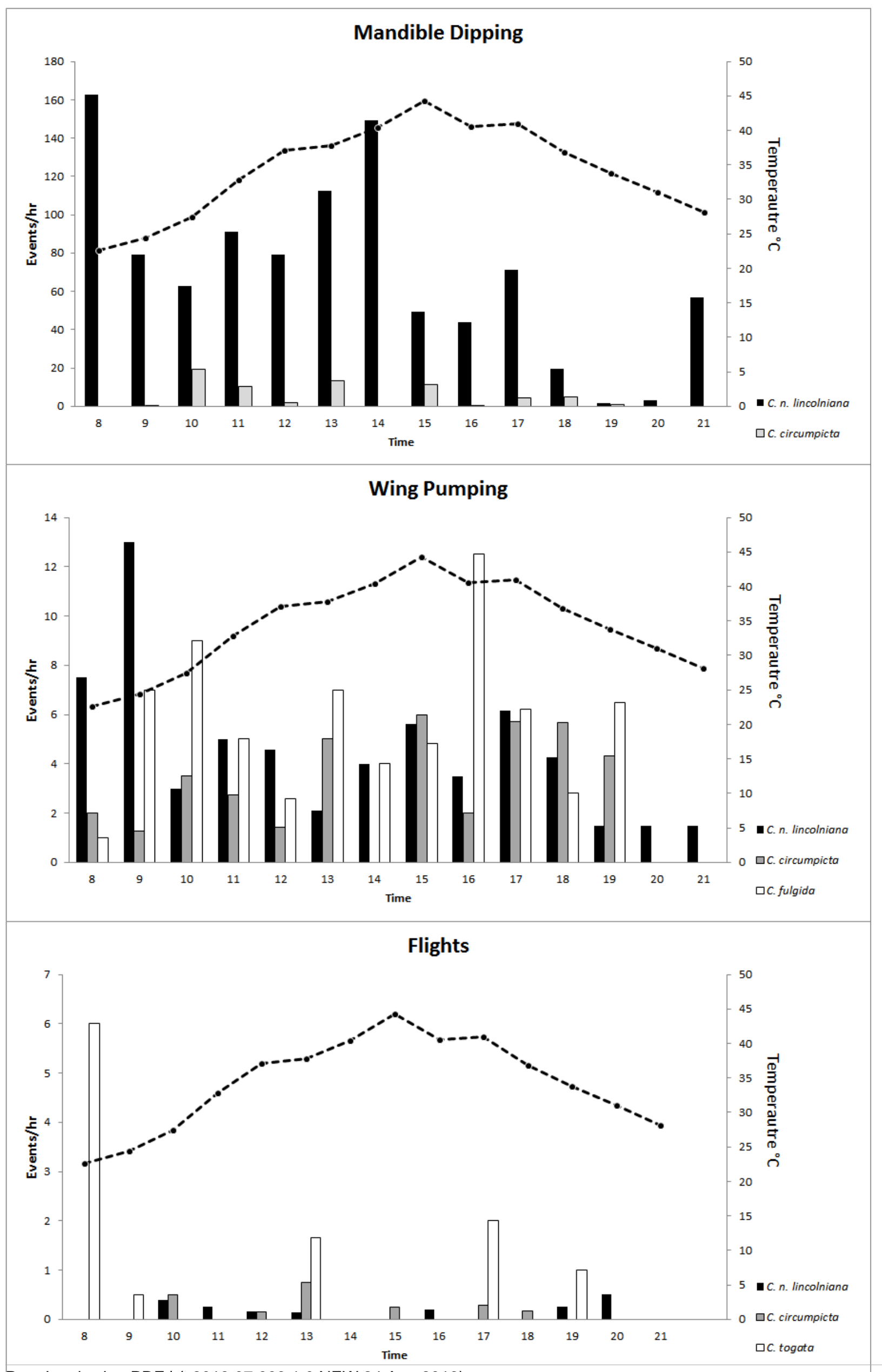

Peerd reviewing PDF | (v2013:07:669:1:0:NEW 24 Aug 2013) 